\title{
The Effect of Sn Content on Mechanical, Magnetization and Shape Memory Behavior in NiMnSn Alloys
}

\author{
Y. Aydogdu, ${ }^{\mathrm{a},}$, A. S. Turabi ${ }^{\mathrm{b}}$, M. Kok ${ }^{\mathrm{c}}$, A. Aydogdu', Z. D. Yakinci ${ }^{\mathrm{d}}$, M. A. Aksan ${ }^{\mathrm{e}}$, M. E. \\ Yakinci $^{f}$, H. E. Karaca ${ }^{\mathrm{b}}$ \\ ${ }^{a}$ Department of Physics, Faculty of Science, Gazi University, Ankara, Turkey \\ ${ }^{b}$ Department of Mechanical Engineering, University of Kentucky, Lexington KY 40506, USA \\ 'Department of Physics, Faculty of Science, Firat University, Elazig, Turkey \\ ${ }^{d}$ Vocational School of Health Service, Inonu University, Malatya, Turkey \\ eDepartment of Physics, Faculty of Arts and Science, Inonu University, Malatya, Turkey \\ ${ }^{\mathrm{f}}$ Department of Biomedical Engineering, Faculty of Engineering, Inonu University, Malatya, \\ Turkey \\ "Corresponding Author: y.aydogdu@gazi.edu.tr
}

\begin{abstract}
The effects of the composition alteration on the magnetization and shape memory behavior of $\mathrm{Ni}_{50} \mathrm{Mn}_{40-\mathrm{x}} \mathrm{Sn}_{10+\mathrm{x}}(\mathrm{x}=0,1,2,3)$ alloys were systematically investigated by thermal, magnetic and mechanical experiments. Phase transformation from ferromagnetic austenite to weakly magnetic martensite was observed during thermal cycling under magnetic field and transformation temperatures were decreased with increasing Sn (or decreasing Mn). Moreover, the saturation magnetization of martensite increased with $\mathrm{Sn}$ content. Ni50 $\mathrm{Mn}_{40} \mathrm{Sn}_{10}$ showed the recoverable strain of $2.1 \%$ during thermal cycling under $300 \mathrm{MPa}$ and the reversible superelastic strain of 2 $\%$ at $190{ }^{\circ} \mathrm{C}$. Mechanical experiments exhibited that the largest compressive deformation of about $7 \%$ at $650 \mathrm{MPa}$ occurred in $\mathrm{Ni}_{50} \mathrm{Mn}_{39} \mathrm{Sn}_{11}$ while $\mathrm{Ni}_{50} \mathrm{Mn}_{40} \mathrm{Sn}_{10}$ had fractured at $4 \%$ and $390 \mathrm{MPa}$ at room temperature.
\end{abstract}

Keywords: shape memory, composition alteration, superelasticity, phase transformation, saturation magnetization

\section{Introduction}

NiMn-based Heusler alloys have the ability to undergo a first order magneto-structural transformation from the ferromagnetic austenite to the weakly magnetic martensite where a large magnetization difference $(\Delta M)$ between transforming phases can be observed. As a result of this large magnetization difference and phase transformation, they could demonstrate magnetic shape 
memory effect [1, 2], magnetocaloric effect [3], magnetoresistance [4], magnetothermal conductivity [5] and the elastocaloric effect [6]. It should be noted that the magnetocaloric properties of NiMn-based alloys are comparable to those of $\mathrm{Gd}_{5}(\mathrm{GeSe})_{4}$ alloys [7, 8].

Sutou et al. reported that metamagnetic NiMnX $(X=I n, S n$ and $\mathrm{Sb})$ thermally transforms from ferromagnetic austenite (cubic crystal structured) to weakly magnetic martensite (orthorhombic four layered crystal structured) with high mobility of twins, which increases the possibility of observing large magnetic field induced strain in NiMn-based Heusler alloys [9]. NiMnSn alloys have been studied extensively as an inexpensive alternative to NiMnGa and NiMnIn magnetic shape memory alloys. Thus, they can be employed in large scale applications such as magnetic actuators, high-efficiency sensors, and environment-friendly magnetic refrigerators.

In MSMAs, the valence electron concentration $(e / a)$ is frequently used to relate the phase transition temperatures to composition $[10,11]$. In NiMnSn alloys, the crystal structure of the martensite evolves in a sequence of $4 O \rightarrow 10 M \rightarrow 14 M \rightarrow L 1_{0}$ with increasing $e / a$ [12]. It should be noted that the magnetic and shape memory properties of NiMnSn alloys are highly martensite morphology, crystal structure, and lattice parameter dependent [12, 13]. Thus, composition alteration can be used as a very effective method to tailor the material properties of NiMnSn alloys.

The effects of composition on microstructure, thermal, and magnetic properties of NiMnSn alloys have been investigated previously [14-19]. Zheng et al. reported that the transformation temperatures increase dramatically by increasing Mn content in $\mathrm{Ni}_{50} \mathrm{Mn}_{37+\mathrm{x}} \mathrm{Sn}_{13-\mathrm{x}}$ and the increase of transformation temperatures is directly related to the change of e/a ratio and the unit cell volume of high temperature austenite [20]. In addition, Krenke at al. presented that transformation enthalpy increases with $\mathrm{Mn}$ content by increasing the e/a ratio in $\mathrm{Ni}_{0.50} \mathrm{Mn}_{0.50-\mathrm{x}} \mathrm{Sn}_{\mathrm{x}}$ [12]. Han et al. [11] reported that magnetization difference between the transforming phases of $\mathrm{Ni}_{50-\mathrm{x}} \mathrm{Mn}_{39+\mathrm{x}} \mathrm{Sn}_{11}$ were studied by increased with $\mathrm{Mn}$ and large inverse magnetic entropy change was observed under $1 \mathrm{~T}$ which makes these alloys promising for magnetic refrigeration applications.

In general, other than transformation temperatures, the shape memory properties (e.g transformation strain, critical stress for phase transformation, hysteresis) of NiMnSn alloys under stress have not been studied thoroughly even though they are essential for practical applications. 
In this study, the effects of composition on the transformation temperatures, microstructure and magnetization behavior of $\mathrm{Ni}_{50} \mathrm{Mn}_{40-\mathrm{x}} \mathrm{Sn}_{10+\mathrm{x}}$ alloys were systematically characterized. Then, the thermal cycling under stress, superelasticity and fracture tests were conducted to reveal shape memory and mechanical behavior of these alloys to establish a composition-property relationship.

\section{Material and Experimental Methods}

$\mathrm{Ni}_{50} \mathrm{Mn}_{40-\mathrm{x}} \mathrm{Sn}_{10+\mathrm{x}}($ at. \%) $(\mathrm{x}=0,1,2,3)$ polycrystalline alloys were fabricated by vacuum arc melting method in a water cooled $\mathrm{Cu}$ crucible by using Nickel with purity of $99.8 \%$, Manganese with purity of $99.9 \%$ and Sn with purity of $99.9 \%$. The ingots were melted several times to ensure homogenization and then they were annealed at $900{ }^{\circ} \mathrm{C}$ for 17 hours. Microstructural analysis of the samples was performed by using Scanning Electron Microscope (SEM; Leo EVO-40 VPX) and their chemical composition was determined by Energy Dispersive X-ray Spectroscopy (EDS; Bruker-125eV). The compositions (at. \%) of the fabricated alloys were determined as Ni49Mn40.4Sn10.6, Ni49.5Mn38.9Sn11.6, Ni48.3Mn38.Sn12.7 and Ni49.4Mn36.9Sn13.7. Transformation temperatures were determined by Perkin Elmer Differential Scanning Calorimetry (DSC) with 10 ${ }^{\circ} \mathrm{C} / \mathrm{min}$ heating-cooling rate in a nitrogen atmosphere. In order to reveal the microstructure of the alloys, specimens were polished and etched with a solution of $20 \mathrm{ml} \mathrm{HCl}, 5 \mathrm{~g} \mathrm{FeCl}_{3}-\mathrm{H}_{2} \mathrm{O}$ and 96 $\mathrm{ml}$ methanol. Magnetization properties were measured by Physical property measurement system (PPMS) (Quantum Design 7). Metal-tester Vickers microhardness tester model 900-391D was employed for hardness measurements. The mechanical experiments were conducted on $3 \times 3 \times 6$ $\mathrm{mm}^{3}$ compression samples by using MTS Landmark servohydraulic test frame. Thermal cycling experiments were performed with the rates of 5 and $10{ }^{\circ} \mathrm{C} / \mathrm{min}$ for cooling and heating, respectively. The strain was measured by an MTS high temperature extensometer with a gage length of $12 \mathrm{~mm}$.

\section{Results and Discussions}

Figure 1a shows the DSC responses of $\mathrm{Ni}_{50} \mathrm{Mn}_{40-\mathrm{x}} \mathrm{Sn}_{10+\mathrm{x}}$ alloys where reversible martensitic phase transformation was observed in all alloys. Transformation temperatures (TTs) such as martensite and austenite start, finish and peak temperatures $\left(\mathrm{M}_{\mathrm{p}}\right.$ and $\left.\mathrm{A}_{\mathrm{p}}\right)$ and transformation enthalpy were determined from Figure 1a and given in Table 1. Moreover, the e/a ratio and Vickers hardness measurements of the alloys were also provided in Table 1. TTs were decreased with the substitution of Mn with $\mathrm{Sn}$. For instance, martensite start $\left(\mathrm{M}_{\mathrm{s}}\right)$, martensite finish $\left(\mathrm{M}_{\mathrm{f}}\right)$, austenite 
start $\left(A_{s}\right)$, and austenite finish $\left(A_{f}\right)$ temperatures were $216.9,181.9,195.5$ and $227.6{ }^{\circ} \mathrm{C}$ for $\mathrm{Ni}_{50} \mathrm{Mn}_{40} \mathrm{Sn}_{10}$ and $45.5,2.9,23$ and $66.1{ }^{\circ} \mathrm{C}$ for $\mathrm{Ni}_{50} \mathrm{Mn}_{37} \mathrm{Sn}_{13}$, respectively. It is clear that substitution of Mn with Sn decreases both the e/a ratio and transformation temperatures as shown in Figure 1b. The linear relationship between the e/a ratio and the martensite start temperature of $\mathrm{Ni}_{50} \mathrm{Mn}_{40-\mathrm{x}} \mathrm{Sn}_{10+x}$ alloys is consistent with the previous results [21]. In order to determine the effect of Sn content on mechanical behavior in terms of strength, Vickers hardness measurements were performed and showed that $\mathrm{Ni}_{50} \mathrm{Mn}_{39} \mathrm{Sn}_{11}$ has the lowest hardness and $\mathrm{Ni}_{50} \mathrm{Mn}_{40} \mathrm{Sn}_{10}$ has the highest hardness at room temperature. It would worth to mention that the strength is decreased with increasing Sn content. Furthermore, enthalpy $(\Delta \mathrm{H})$ values were extracted from DSC curves during phase transformations. $\Delta \mathrm{H}$ was increased initially and then decreased with Sn content as shown in Table 1.

It should be noted that a two-stage transformation was only observed in $\mathrm{Ni}_{50} \mathrm{Mn}_{40} \mathrm{Sn}_{10}$. The second peak of transformation temperatures is referred as $\mathrm{Ms}^{2}, \mathrm{Mf}^{2}, \mathrm{As}^{2}$ and $\mathrm{Af}^{2}$ and they were obtained as $171.2{ }^{\circ} \mathrm{C}, 87.5{ }^{\circ} \mathrm{C}, 102{ }^{\circ} \mathrm{C}$ and $186.6{ }^{\circ} \mathrm{C}$, respectively. The second peak in $\mathrm{Ni}_{50} \mathrm{Mn}_{40} \mathrm{Sn}_{10}$ might be attributed to intermartensitic phase transformation or inhomogeneous microstructure [9, 20, 22].

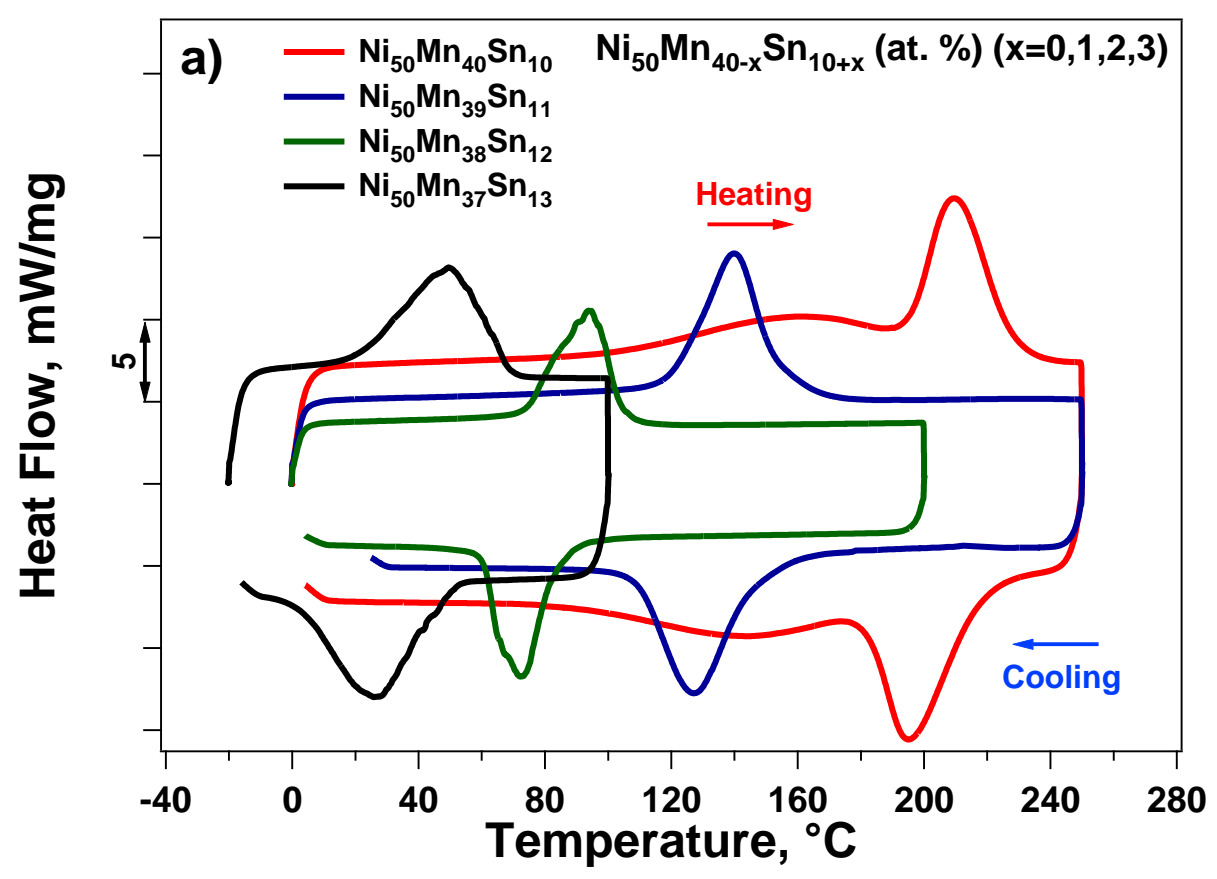




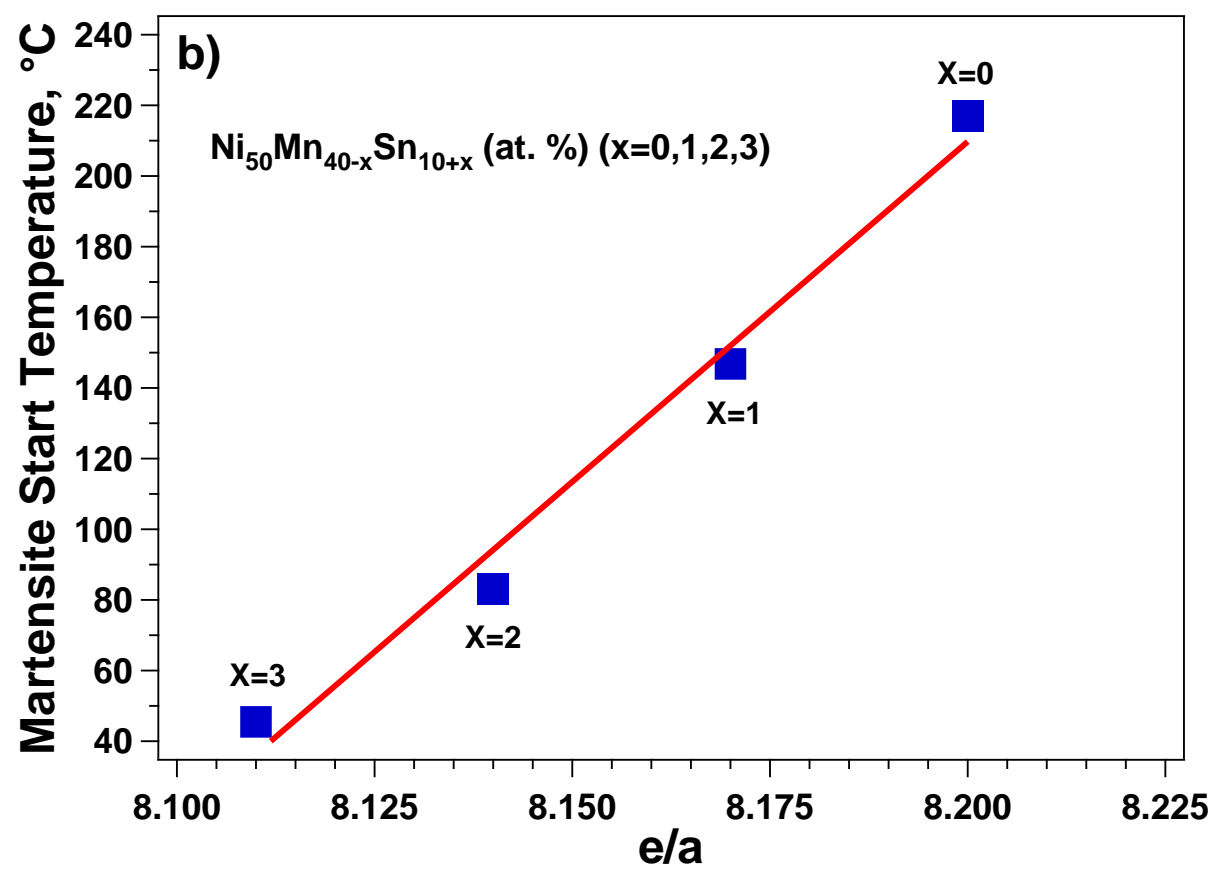

Figure 1. a) DSC response, b) $\mathrm{M}_{\mathrm{s}}$ temperature as a function of e/a ratio in of $\mathrm{Ni}_{50} \mathrm{Mn}_{40-\mathrm{x}} \mathrm{Sn}_{10+\mathrm{x}}$ alloys

Table 1. Transformation temperatures and enthalpies, e/a ratios and Vicker hardness of Nis0Mn40x $\mathrm{Sn}_{10+\mathrm{x}}$ alloys

\begin{tabular}{|c|c|c|c|c|c|c|c|c|c|}
\hline & $\begin{array}{l}\mathbf{M}_{\mathrm{s}} \\
\left({ }^{\circ} \mathbf{C}\right)\end{array}$ & $\begin{array}{l}\mathbf{M}_{\mathbf{p}} \\
\left({ }^{\circ} \mathbf{C}\right)\end{array}$ & $\begin{array}{l}\mathbf{M}_{\mathbf{f}} \\
\left({ }^{\circ} \mathbf{C}\right)\end{array}$ & $\begin{array}{c}\mathbf{A}_{\mathbf{s}} \\
\left({ }^{\circ} \mathbf{C}\right)\end{array}$ & $\begin{array}{c}\mathbf{A}_{\mathbf{p}} \\
\left({ }^{\circ} \mathbf{C}\right)\end{array}$ & $\begin{array}{c}\mathbf{A}_{\mathbf{f}} \\
\left({ }^{\circ} \mathbf{C}\right)\end{array}$ & $\begin{array}{c}\Delta \mathbf{H}_{\text {avg }} \\
(\mathrm{J} / \mathrm{g})\end{array}$ & e/a & $\begin{array}{c}\text { Hardness } \\
\text { (HV) }\end{array}$ \\
\hline $\mathbf{N i}_{50} \mathbf{M n}_{40} \mathbf{S n}_{10}$ & 216.9 & 195.6 & 181.9 & 195.5 & 209.9 & 227.6 & 12.65 & 8.2 & 451 \\
\hline $\mathrm{Ni}_{50} \mathrm{Mn}_{39} \mathrm{Sn}_{11}$ & 146.8 & 127.2 & 108.3 & 120.3 & 139.9 & 154.6 & 19.96 & 8.17 & 309 \\
\hline $\mathrm{Ni}_{50} \mathrm{Mn}_{38} \mathrm{Sn}_{12}$ & 83 & 72.2 & 60.3 & 73 & 93.8 & 103.3 & 17.95 & 8.14 & 397 \\
\hline $\mathrm{Ni}_{50} \mathrm{Mn}_{37} \mathrm{Sn}_{13}$ & 45.5 & 26.4 & 2.9 & 23 & 49.4 & 66.1 & 14.30 & 8.11 & 351 \\
\hline
\end{tabular}

From Figure 1, it is clear that $\mathrm{Ni}_{50} \mathrm{Mn}_{40} \mathrm{Sn}_{10}, \mathrm{Ni}_{50} \mathrm{Mn}_{39} \mathrm{Sn}_{11}$ and $\mathrm{Ni}_{50} \mathrm{Mn}_{38} \mathrm{Sn}_{12}$ are fully martensite while $\mathrm{Ni}_{50} \mathrm{Mn}_{37} \mathrm{Sn}_{13}$ can be mixed phase or fully martensite (depending on the cooling history) at room temperature. Since they were all martensite at room temperature and no second phase formation was observed, only a representative SEM image of $\mathrm{Ni}_{50} \mathrm{Mn}_{38} \mathrm{Sn}_{12}$ is shown in Figure 2. Yellow circles indicate where SEM/EDS composition analysis was performed. The martensite structures can clearly be seen in the image. Furthermore, XRD experiments were performed at room temperature on bulk fabricated samples (not shown here) and it was revealed that the martensite is either $10 \mathrm{M}$ or $14 \mathrm{M}$ in $\mathrm{Ni}_{50} \mathrm{Mn}_{40} \mathrm{Sn}_{10}$ and $\mathrm{Ni}_{50} \mathrm{Mn}_{39} \mathrm{Sn}_{11}$ alloys and $4 \mathrm{O}$ in 
$\mathrm{Ni}_{50} \mathrm{Mn}_{38} \mathrm{Sn}_{12}$ and $\mathrm{Ni}_{50} \mathrm{Mn}_{37} \mathrm{Sn}_{13}$ alloys. The diffraction patterns were found to be in good agreement with previous results [20].

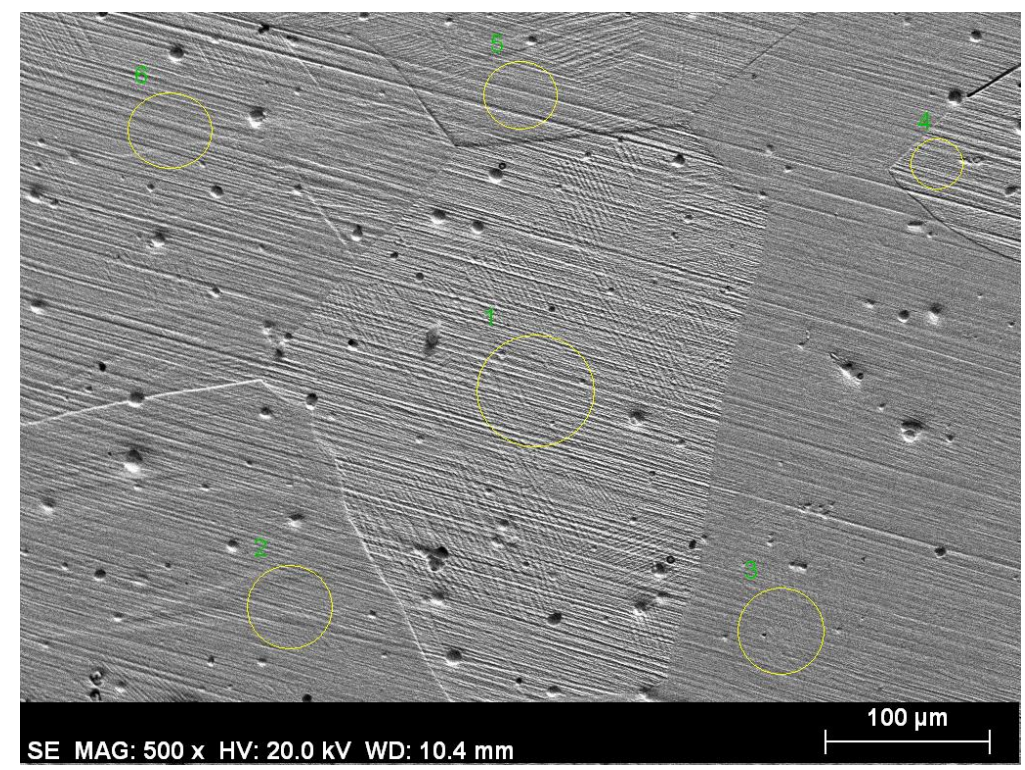

Figure 2. SEM image of $\mathrm{Ni}_{50} \mathrm{Mn}_{38} \mathrm{Sn}_{12}$ alloy

Magnetization versus temperature responses of $\mathrm{Ni}_{50} \mathrm{Mn}_{40-\mathrm{x}} \mathrm{Sn}_{10+\mathrm{x}}$ alloys under $5 \mathrm{~T}$ are shown in Figure 3. All the samples were heated from $30{ }^{\circ} \mathrm{C}$ to $270{ }^{\circ} \mathrm{C}$ and then cooled down to 30 ${ }^{\circ} \mathrm{C}$ under constant field of $5 \mathrm{~T}$. During heating of $\mathrm{Ni}_{50} \mathrm{Mn}_{40} \mathrm{Sn}_{10}, \mathrm{Ni}_{50} \mathrm{Mn}_{39} \mathrm{Sn}_{11}$, and $\mathrm{Ni}_{50} \mathrm{Mn}_{38} \mathrm{Sn}_{12}$ alloys, ferromagnetic martensite becomes weakly magnetic as the temperature approaches to the Curie temperature of martensite. Then, martensite transforms to ferromagnetic austenite which is evidenced by the sudden increase in the magnetization. With further heating, the magnetization of austenite decreases as the temperature approaches to the Curie temperature of austenite. The TTS can be obtained from magnetization results with intersection method. It is clear that TTs were decreased with Sn content which is in good agreement with the DSC results shown in Figure 1. Phase transformation upon heating was not observed in $\mathrm{Ni}_{50} \mathrm{Mn}_{37} \mathrm{Sn}_{13}$ since it was austenite at 30 ${ }^{\circ} \mathrm{C}$. It should also be noted that $\mathrm{Ni}_{50} \mathrm{Mn}_{40} \mathrm{Sn}_{10}$ showed two-stage transformation which was also detected in its DSC response. 

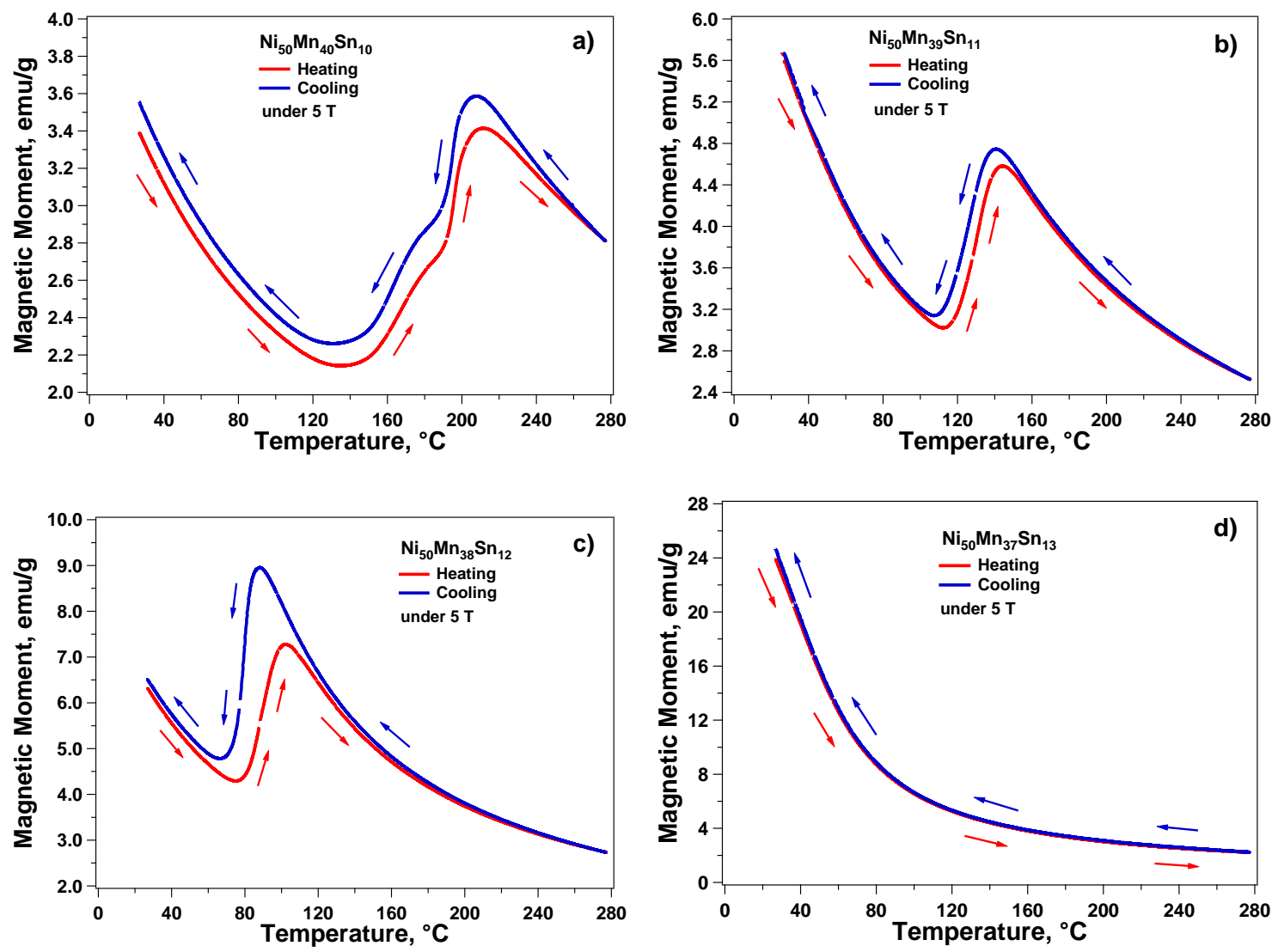

Figure 3. Magnetization versus temperature responses of a) $\mathrm{Ni}_{50} \mathrm{Mn}_{40} \mathrm{Sn}_{10}$, b) $\mathrm{Ni}_{50} \mathrm{Mn}_{39} \mathrm{Sn}_{11}$, c) $\mathrm{Ni}_{50} \mathrm{Mn}_{38} \mathrm{Sn}_{12}$ and d) $\mathrm{Ni}_{50} \mathrm{Mn}_{37} \mathrm{Sn}_{13}$ alloys under $5 \mathrm{~T}$

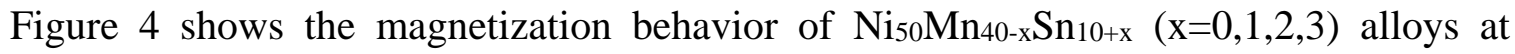
selected temperatures of $-100{ }^{\circ} \mathrm{C}, 30^{\circ} \mathrm{C}$ and $250{ }^{\circ} \mathrm{C}$. At $-100{ }^{\circ} \mathrm{C}$, all the alloys are ferromagnetic and the saturation magnetization was increased with $\mathrm{Sn}$ where the saturation magnetization of $\mathrm{Ni}_{50} \mathrm{Mn}_{40} \mathrm{Sn}_{10}, \mathrm{Ni}_{50} \mathrm{Mn}_{39} \mathrm{Sn}_{11}, \mathrm{Ni}_{50} \mathrm{Mn}_{38} \mathrm{Sn}_{12}$ and $\mathrm{Ni}_{50} \mathrm{Mn}_{37} \mathrm{Sn}_{13}$ were determined as 12.4, 16.6, 21.9 and $33.1 \mathrm{emu} / \mathrm{g}$, respectively. The alteration of saturation magnetization can be attributed to the modification of the exchange interactions of the atoms in the alloy. Mn atoms can be coupled ferromagnetically or anti-ferromagnetically by altering the composition which in turn affects the saturation magnetization $[23,24]$. Figure $4 \mathrm{~b}$ shows that the magnetization of $\mathrm{Ni}_{50} \mathrm{Mn}_{37} \mathrm{Sn}_{13}$ was drastically increased and then saturated with magnetic field at $30{ }^{\circ} \mathrm{C}$ while the magnetization of the other alloys showed linear behavior with a low magnetic moment of about $5 \mathrm{emu} / \mathrm{g}$. It should be noted that $\mathrm{Ni}_{50} \mathrm{Mn}_{37} \mathrm{Sn}_{13}$ can have mixed phases while the other alloys were martensite at $30{ }^{\circ} \mathrm{C}$. Thus, $\mathrm{Ni}_{50} \mathrm{Mn}_{37} \mathrm{Sn}_{13}$ alloy presented higher magnetization of about $24 \mathrm{emu} / \mathrm{g}$ due to ferromagnetic 
austenite. For all the alloys, the magnetization was increased linearly with the magnetic field at $250{ }^{\circ} \mathrm{C}$, above their Curie temperature of austenite, as shown in Figure 4c.
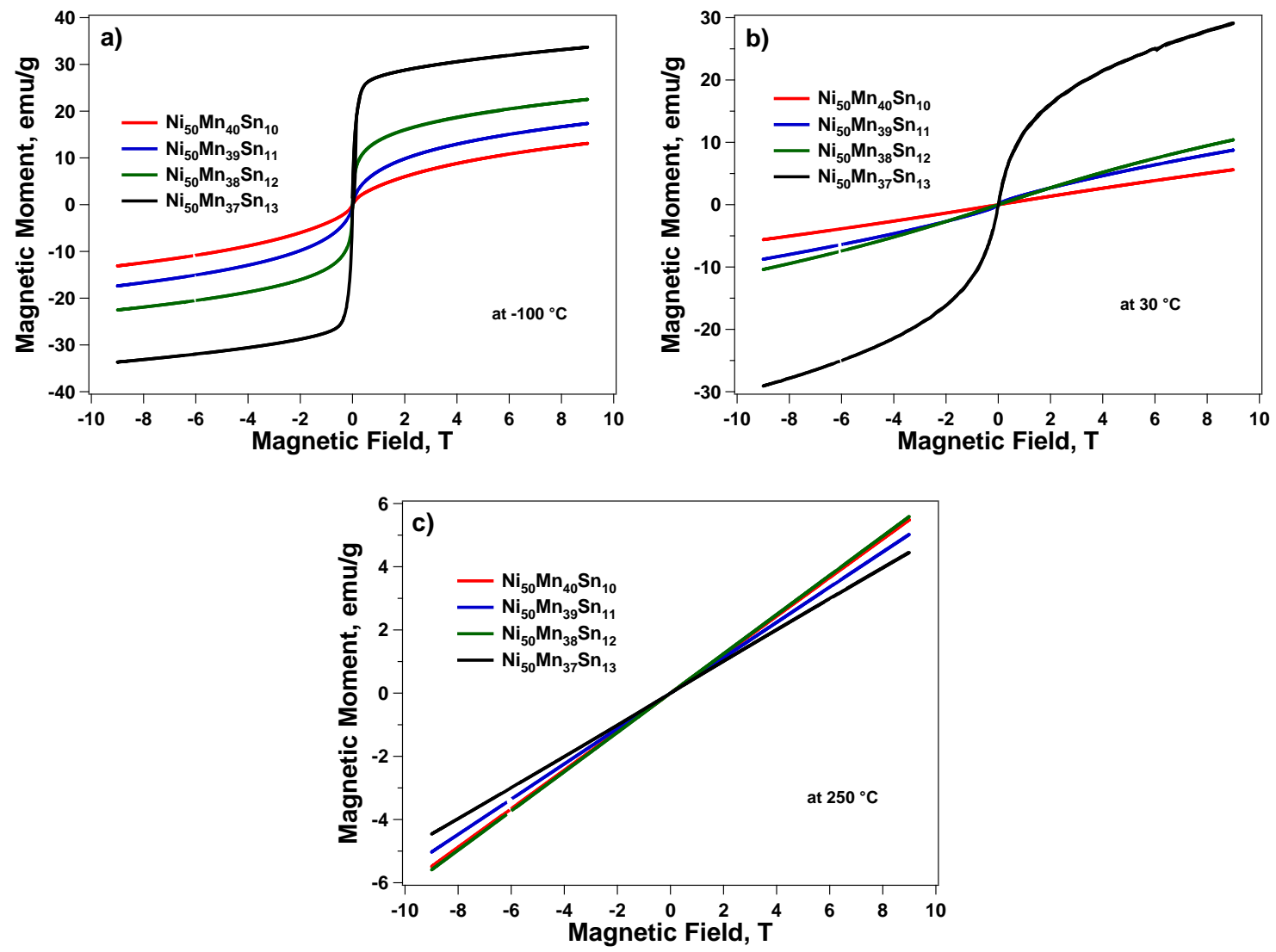

Figure 4. Magnetization behavior of $\mathrm{Ni}_{50} \mathrm{Mn}_{40-\mathrm{x}} \mathrm{Sn}_{10+\mathrm{x}}$ alloys at a) $-100{ }^{\circ} \mathrm{C}$, b) $30{ }^{\circ} \mathrm{C}$, c) $250{ }^{\circ} \mathrm{C}$

In order to obtain information on the shape memory behavior of $\mathrm{Ni}_{50} \mathrm{Mn}_{40-\mathrm{x}} \mathrm{Sn}_{10+\mathrm{x}}$ alloys, they were thermally cycled under selected stress levels, as shown in Figure 5. Upon cooling, austenite transforms to martensite while martensite transforms back to austenite upon heating. Maximum applied stress was $300 \mathrm{MPa}$ for $\mathrm{Ni}_{50} \mathrm{Mn}_{40} \mathrm{Sn}_{10}$ and $\mathrm{Ni}_{50} \mathrm{Mn}_{39} \mathrm{Sn}_{11}$ samples and 200, 250 MPa for Ni50Mn38Sn12 and Ni50Mn37Sn13 samples, respectively. Ni50Mn39Sn11 and Ni50Mn37Sn13 samples failed during heating under 300 and $250 \mathrm{MPa}$, respectively. The transformation temperatures were obtained graphically by intersection method and found to be increasing with stress. Generally, there is a linear relationship between $\mathrm{M}_{\mathrm{s}}$ and applied stress which is known as Clausius Clapeyron phenomenon [25]. The $\mathrm{M}_{\mathrm{s}}, \mathrm{M}_{\mathrm{f}}, \mathrm{A}_{\mathrm{s}}$ and $\mathrm{A}_{\mathrm{f}}$ of $\mathrm{Ni}_{50} \mathrm{Mn}_{40} \mathrm{Sn}_{10}$ were obtained as 177.4, 160.8, 170 and $180.3{ }^{\circ} \mathrm{C}$ under $5 \mathrm{MPa}$ and 203.8, 169.8, 186.9 and $215^{\circ} \mathrm{C}$ under $300 \mathrm{MPa}$, respectively. $\mathrm{M}_{\mathrm{s}}$ of $\mathrm{Ni}_{50} \mathrm{Mn}_{40} \mathrm{Sn}_{10}, \mathrm{Ni}_{50} \mathrm{Mn}_{39} \mathrm{Sn}_{11}, \mathrm{Ni}_{50} \mathrm{Mn}_{38} \mathrm{Sn}_{12}$, and $\mathrm{Ni}_{50} \mathrm{Mn}_{37} \mathrm{Sn}_{13}$ were 
determined as $177.4,149.7,91.3$ and $57.1{ }^{\circ} \mathrm{C}$, respectively, under $5 \mathrm{MPa}$. It is clear that TTs decreased with Sn content which is good agreement with DSC and magnetization results.

The difference between the Ms obtained from DSC and mechanical tests (about 5 to $15^{\circ} \mathrm{C}$ ) can be attributed to several reasons. i) DSC tests were conducted in a fully enclosed environment with a small amount of material ( $20 \mathrm{mg})$ while thermal cycling tests had been done by conduction heating on a large sample ( $\sim \mathrm{g})$. ii) In mechanical tests, the change in sample length is due to the formation of reoriented martensite variants and the formation of the self accommodating martensite cannot be detected. Thus, particularly at lower stress levels (e.g. 5 or $50 \mathrm{MPa}$ ) where the volume fraction reoriented martensite variants is low, the phase transformation may start earlier than what can be detected. iii) The accuracy of the intersection methods used to determine the TTs depends on shape of the curves. 

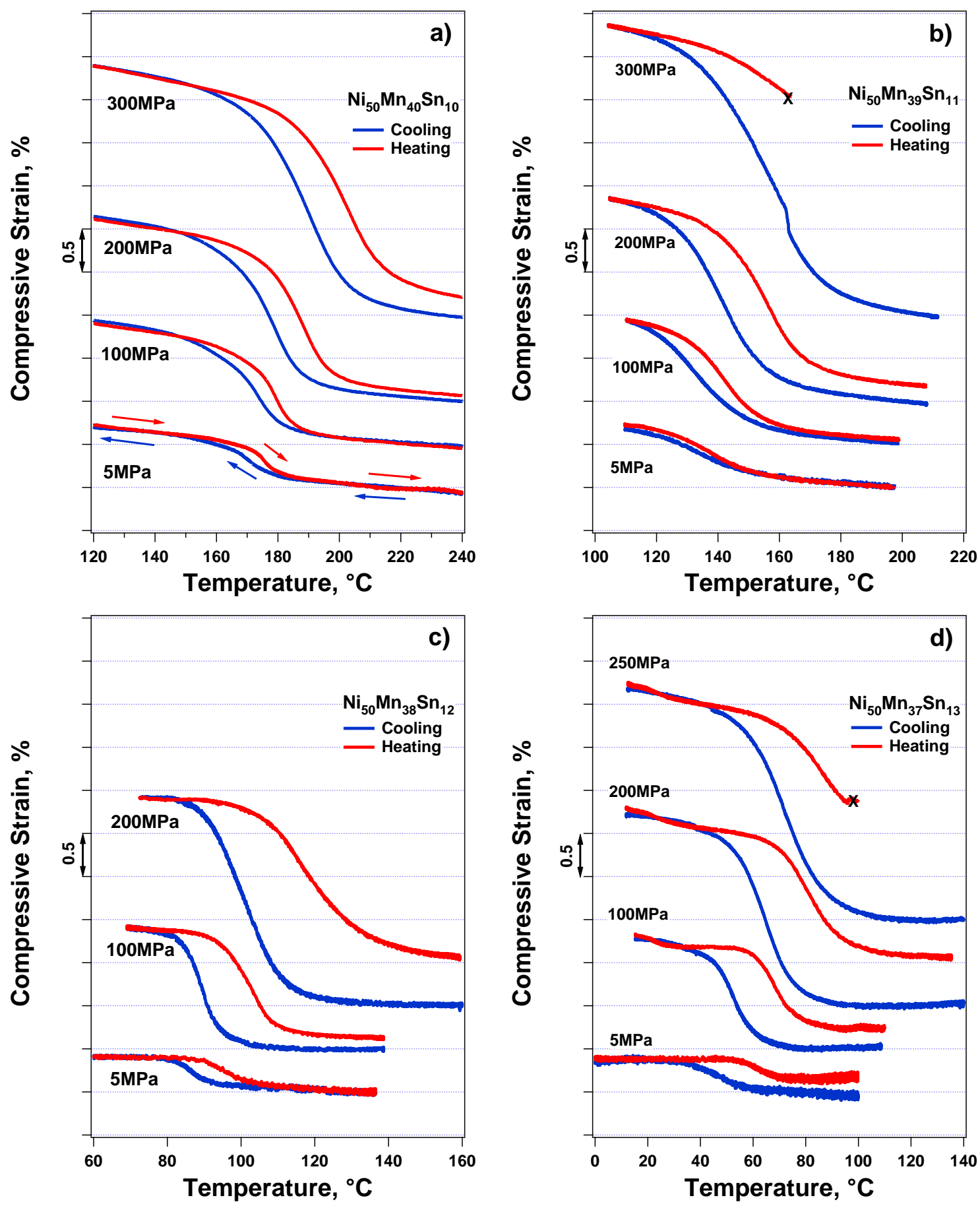

Figure 5. Thermal cycling responses of $\mathrm{Ni}_{50} \mathrm{Mn}_{40-\mathrm{x}} \mathrm{Sn}_{10+x}$ alloys under selected stress levels

Recoverable strain, temperature hysteresis and irrecoverable strain of Ni50 Mn40-x $\mathrm{Sn}_{10+x}$ alloys were extracted from Figure 5 and plotted as a function of applied stress in Figure 6. The recoverable strain increased with stress due to the increased volume fraction of favored martensite variants. The recoverable strain was $0.4 \%$ under $5 \mathrm{MPa}$ and increased to $2.1 \%$ under $300 \mathrm{MPa}$ in 
$\mathrm{Ni}_{50} \mathrm{Mn}_{40} \mathrm{Sn}_{10}$. In addition, Irrecoverable strain increases with stress. Irrecoverable strain of $\mathrm{Ni}_{50} \mathrm{Mn}_{37} \mathrm{Sn}_{13}$ was $0.1 \%$ under $50 \mathrm{MPa}$ and increased to $0.6 \%$ under $200 \mathrm{MPa}$. The maximum recoverable and irrecoverable strains were 2.1 and $0.2 \%$ under $300 \mathrm{MPa}$ in $\mathrm{Ni}_{50} \mathrm{Mn}_{40} \mathrm{Sn}_{10}$ while they were 1.5 and $0.5 \%$ under $200 \mathrm{MPa}$ in $\mathrm{Ni}_{50} \mathrm{Mn}_{37} \mathrm{Sn}_{13}$ alloy, respectively. It should be noted from Figure $6 \mathrm{~b}$ that for the same stress level, irrecoverable strain increases with Sn due to increased plastic deformation. Temperature hysteresis mainly arises from structural defect formation, such as dislocations, during transformation and frictional energy spent on the movement of phase fronts [26]. Hysteresis highly depends on the lattice compatibility between transforming phases which is dictated by the crystal structure and parameters that can be tailored by composition alteration. In general, temperature hysteresis increases with increasing applied stress due to increased plastic deformation, as shown in Figure 6b. The maximum temperature hysteresis of $\mathrm{Ni}_{50} \mathrm{Mn}_{40} \mathrm{Sn}_{10}$ and $\mathrm{Ni}_{50} \mathrm{Mn}_{37} \mathrm{Sn}_{13}$ alloys were obtained as 13.3 and $20.8{ }^{\circ} \mathrm{C}$ under 300 and $200 \mathrm{MPa}$, respectively.
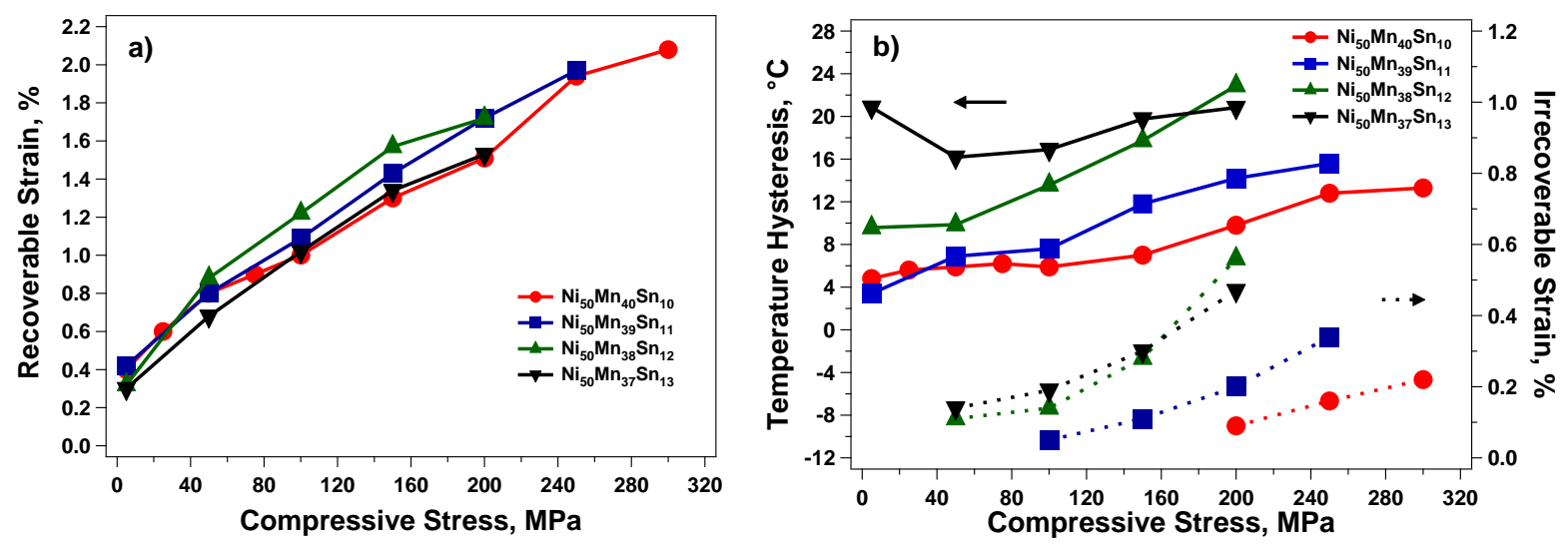

Figure 6. a) Recoverable strain, and b) temperature hysteresis and irrecoverable strain as a function of compressive stress for $\mathrm{Ni}_{50} \mathrm{Mn}_{40-\mathrm{x}} \mathrm{Sn}_{10+\mathrm{x}}$ alloys

Figure 7 shows the mechanical responses of $\mathrm{Ni}_{50} \mathrm{Mn}_{40-\mathrm{x}} \mathrm{Sn}_{10+x}$ alloys at room temperature. The alloys were loaded until they failed to observe their compressive strength and ductility. It should be noted that, according to the DSC results, at room temperature, all samples are martensite except $\mathrm{Ni}_{50} \mathrm{Mn}_{37} \mathrm{Sn}_{13}$ which is a mixed phase. $\mathrm{Ni}_{50} \mathrm{Mn}_{39} \mathrm{Sn}_{11}$ alloy has the highest failure stress and strain among the tested alloys. Failure stress and strain values were $650 \mathrm{MPa}$ and $7 \%$ for $\mathrm{Ni}_{50} \mathrm{Mn}_{39} \mathrm{Sn}_{11}$ and $390 \mathrm{MPa}$ and $3.9 \%$ for $\mathrm{Ni}_{50} \mathrm{Mn}_{40} \mathrm{Sn}_{10}$, respectively. 


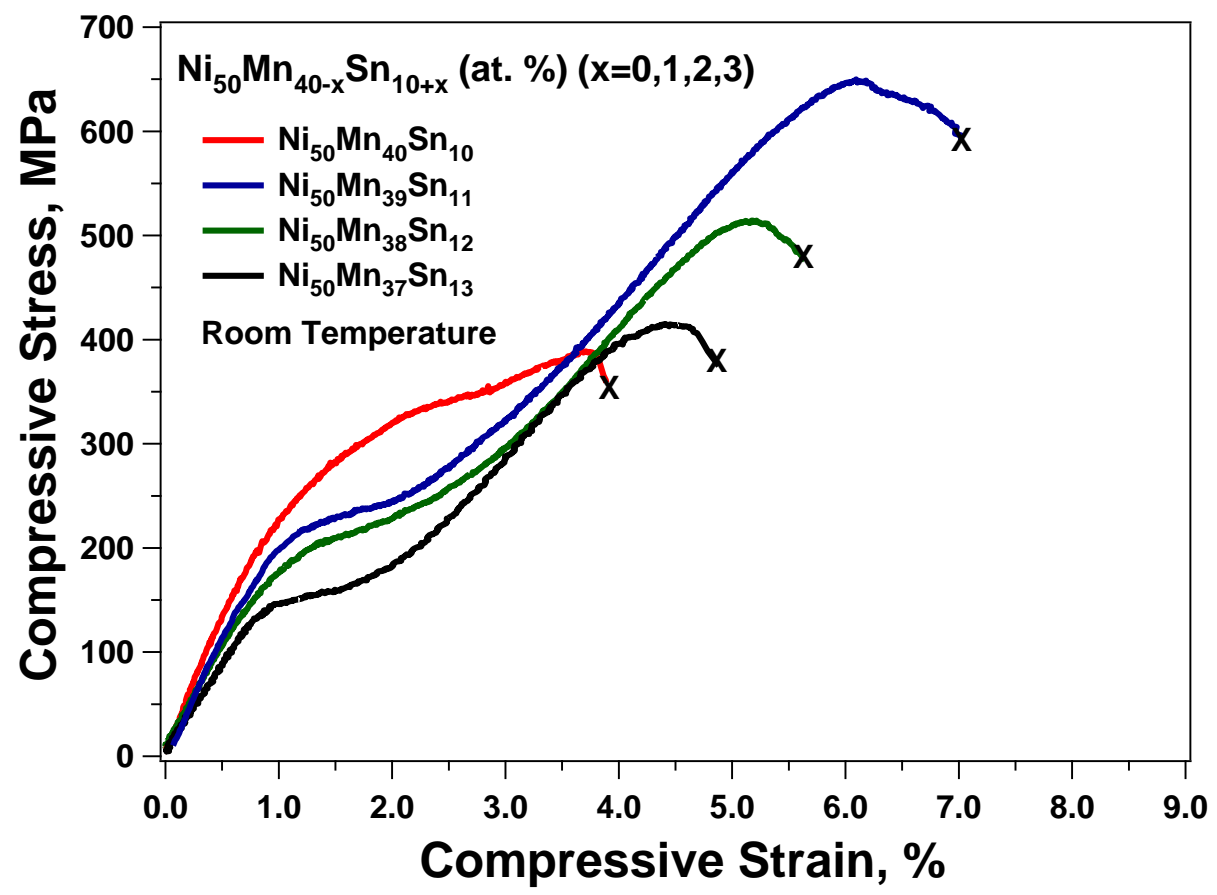

Figure 7. Loading until failure at room temperature for $\mathrm{Ni}_{50} \mathrm{Mn}_{40-\mathrm{x}} \mathrm{Sn}_{10+\mathrm{x}}$ alloys

The superelastic response of $\mathrm{Ni}_{50} \mathrm{Mn}_{40} \mathrm{Sn}_{10}$ is shown in Figure 8. The test temperature of $190{ }^{\circ} \mathrm{C}$ was selected to be above Af to observe superelastic behavior. When the stress was cycled up to $240 \mathrm{MPa}$, the alloy showed superelasticity where it transformed from austenite to martensite upon loading and martensite to austenite transformation was observed upon unloading. Further loading to $360 \mathrm{MPa}$ (with $2 \%$ strain) also resulted in superelastic behavior with a higher stress hysteresis. In both cases, the irrecoverable strain upon unloading was very low, thus, the alloy showed fully reversible superelastic behavior. Further loading to $400 \mathrm{MPa}$ resulted in brittle fracture. It should be noted that this alloy is an high temperature shape memory alloy since it shows superelasticity above $100{ }^{\circ} \mathrm{C}[27]$. 


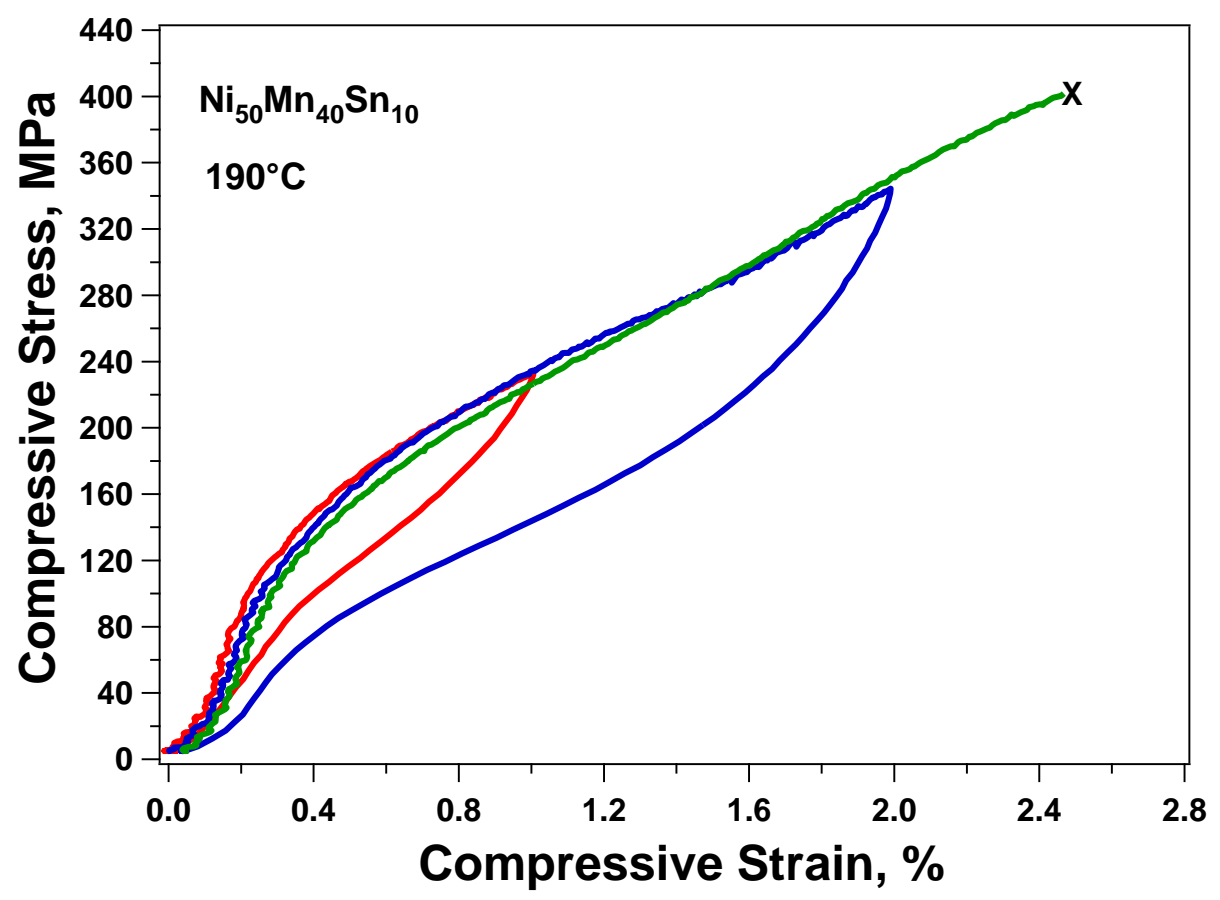

Figure 8. Superelastic response of $\mathrm{Ni}_{50} \mathrm{Mn}_{40} \mathrm{Sn}_{10}$ alloy at $190{ }^{\circ} \mathrm{C}$

It is known that thermal, magnetic and mechanical experiments showed that shape memory, magnetic and mechanical properties of NiMnSn alloys are highly composition dependent [14-19]. Composition variation modifies e/a ratio which alters the transformation temperatures [28] and the crystal structure of martensite (10M, 14M or 4O). Substitution of Mn for Sn in NiMnSn alloys decreased the e/a ratio and the transformation temperatures [12]. Besides, composition variation plays an important role in magnetic behavior of NiMnSn alloys since the magnetic moment is very sensitive to Mn-Mn atom distance in NiMn-based Heusler alloys [29]. In this study, it was revealed that the saturation magnetization of NiMnSn increases with Sn at $100{ }^{\circ} \mathrm{C}$.

Mechanical experiments were conducted to reveal the shape memory effect and superelasticity responses of $\mathrm{Ni}_{50} \mathrm{Mn}_{40-\mathrm{x}} \mathrm{Sn}_{10+\mathrm{x}}$ alloys. There are very limited studies on the mechanical responses of NiMnSn alloys where they were determined to be brittle [30]. It should be noted that brittleness is one of the main setbacks of NiMn-based Heusler alloys for practical applications. Mechanical experiments revealed that strength and ductility can be modified by composition alteration. The strength and ductility initially increased and then decreased with Sn. $\mathrm{Ni}_{50} \mathrm{Mn}_{39} \mathrm{Sn}_{11}$ has the highest failure stress of $650 \mathrm{MPa}$ and can be deformed until $7 \%$ strain at room temperature. Thus, it can be concluded that NiMnSn are not extremely brittle. Alloying with 
quaternary elements can be used as an alternative method to further improve their ductility [3133].

To the authors' knowledge, there is no systematical study on the shape memory effect and superelastic properties of NiMnSn alloys. In this study, it was shown that $\mathrm{Ni}_{50} \mathrm{Mn}_{40} \mathrm{Sn}_{10}$ has a recoverable strain of $2 \%$ during thermal cycling under $300 \mathrm{MPa}$ and superelasticity at $190{ }^{\circ} \mathrm{C}$. Since they are metamagnetic, they could recover their large strains ( 2\%) upon application of magnetic field [34]. It should be noted that magnetostrictives can only recover their shape up to $\sim 0.8 \%$ with applied magnetic field [35]. Thus, NiMnSn magnetic shape memory alloys with high recoverable strain, the ability to show superelasticity and shape memory effect, and tunable transformation temperatures can be considered as promising candidates for magnetic actuator applications.

\section{Conclusions}

Magnetization, shape memory and mechanical properties of $\mathrm{Ni}_{50} \mathrm{Mn}_{40-\mathrm{x}} \mathrm{Sn}_{10+\mathrm{x}}$ alloys were investigated to reveal the effects of Sn content variation. Transformation temperatures decreased with increasing Sn content which can be attributed to e/a ratio. Second phase formation was not observed from optical microscopy. Moreover, metamagnetic behavior was determined from magnetization experiments where ferromagnetic austenite transformed to weakly magnetic martensite. Saturation magnetization increased with Sn content at $-100{ }^{\circ} \mathrm{C}$. Ni50 $\mathrm{Mn}_{40} \mathrm{Sn}_{10}$ showed good shape memory effect with $2.1 \%$ recoverable strain and fully reversible superelasticity at high temperatures $\left(190{ }^{\circ} \mathrm{C}\right)$. Ni50 $\mathrm{Mn}_{39} \mathrm{Sn}_{11}$ failed at $650 \mathrm{MPa}$ and $7 \%$ during compressive deformation. It was concluded that composition alteration is an effective way to tailor transformation temperatures, magnetization response, and mechanical and shape memory properties.

This work is supported by TUBITAK under Project No: 113F234 and National Science Foundation (NSF) CMMI award \#0954541.

\section{References}

[1] R. Kainuma, Y. Imano, W. Ito, Y. Sutou, H. Morito, S. Okamoto, O. Kitakami, K. Oikawa, A. Fujita, T. Kanomata, Nature, 439 (2006) 957-960.

[2] H.E. Karaca, I. Karaman, B. Basaran, Y. Ren, Y.I. Chumlyakov, H.J. Maier, Advanced Functional Materials, 19 (2009) 983-998.

[3] A. Planes, L. Mañosa, M. Acet, Journal of Physics: Condensed Matter, 21 (2009) 233201. 
[4] K. Koyama, H. Okada, K. Watanabe, T. Kanomata, R. Kainuma, W. Ito, K. Oikawa, K. Ishida, Applied physics letters, 89 (2006) 182510-182510.

[5] B. Zhang, X. Zhang, S. Yu, J. Chen, Z. Cao, G. Wu, Applied physics letters, 91 (2007) 012510.

[6] P.O. Castillo-Villa, L. Mañosa, A. Planes, D.E. Soto-Parra, J. Sanchez-Llamazares, H. Flores-Zuniga, C. Frontera, Journal of Applied Physics, 113 (2013) 053506.

[7] D. Rajkumar, M.M. Raja, R. Gopalan, A. Singh, V. Chandrasekaran, K. Suresh, Intermetallics, 18 (2010) 518-522.

[8] T. Krenke, E. Duman, M. Acet, E.F. Wassermann, X. Moya, L. Mañosa, A. Planes, Nature materials, 4 (2005) 450-454.

[9] Y. Sutou, Y. Imano, N. Koeda, T. Omori, R. Kainuma, K. Ishida, K. Oikawa, Applied Physics Letters, 85 (2004) 4358-4360.

[10] T. Krenke, X. Moya, S. Aksoy, M. Acet, P. Entel, L. Mañosa, A. Planes, Y. Elerman, A. Yücel, E. Wassermann, Journal of Magnetism and Magnetic Materials, 310 (2007) 2788-2789.

[11] Z. Han, D. Wang, C. Zhang, H. Xuan, B. Gu, Y. Du, Applied Physics Letters, 90 (2007) 9902.

[12] T. Krenke, M. Acet, E.F. Wassermann, X. Moya, L. Mañosa, A. Planes, Physical Review B, 72 (2005) 014412.

[13] X. Moya, L. Mañosa, A. Planes, T. Krenke, M. Acet, E.F. Wassermann, Materials Science and Engineering: A, 438 (2006) 911-915.

[14] M. Kok, Y. Aydogdu, A.S. Turabi, A. Aydogdu, Z.D. Yakinci, A. M. A, E. M, Yakinci, H.E. Karaca, in: 9 th International Conference on Magnetic and Superconducting Materials, 2015.

[15] B. Ingale, Y. Kuo, S. Ram, IEEE Transactions on Magnetics, 47 (2011) 3395-3398.

[16] M. Nazmunnahar, L. González, J. del Val, J. González, J. Suñol, B. Hernando, IEEE Transactions on Magnetics, 48 (2012) 3749-3752.

[17] E. Passamani, C. Córdova, A. Alves, P. Moscon, C. Larica, A. Takeuchi, A. Biondo, Journal of Physics D: Applied Physics, 42 (2009) 215006.

[18] R.Y. Umetsu, K. Sano, K. Fukushima, T. Kanomata, Y. Taniguchi, Y. Amako, R. Kainuma, Metals, 3 (2013) 225-236.

[19] Z. Ya-Zhuo, C. Jia-Mu, T. Chang-Long, C. Yi-Jiang, C. Wei, Chinese Physics B, 23 (2014) 037504.

[20] H. Zheng, W. Wang, S. Xue, Q. Zhai, J. Frenzel, Z. Luo, Acta Materialia, 61 (2013) 4648-4656.

[21] V. Chernenko, Scripta Materialia, 40 (1999) 523-527.

[22] J. Khalil-Allafi, A. Dlouhy, G. Eggeler, Acta Materialia, 50 (2002) 4255-4274.

[23] R. Umetsu, A. Sheikh, W. Ito, B. Ouladdiaf, K. Ziebeck, T. Kanomata, R. Kainuma, Applied Physics Letters, 98 (2011) 2507.

[24] N. Dan, N. Duc, N. Yen, P. Thanh, L. Bau, N. An, D. Anh, N. Bang, N. Mai, P. Anh, Journal of Magnetism and Magnetic Materials, 374 (2015) 372-375.

[25] S.M. Saghaian, H.E. Karaca, H. Tobe, M. Souri, R. Noebe, Y.I. Chumlyakov, Acta Materialia, 87 (2015) 128-141.

[26] H.E. Karaca, I. Karaman, A. Brewer, B. Basaran, Y.I. Chumlyakov, H.J. Maier, Scripta Materialia, 58 (2008) 815-818.

[27] H.E. Karaca, E. Acar, H. Tobe, S.M. Saghaian, Materials Science and Technology (United Kingdom), 30 (2014) 1530-1544.

[28] V. Chernenko, J. Pons, C. SeguI, E. Cesari, Acta Materialia, 50 (2002) 53-60.

[29] L. Mañosa, X. Moya, A. Planes, T. Krenke, M. Acet, E. Wassermann, Materials Science and Engineering: A, 481 (2008) 49-56.

[30] Y. Feng, J. Sui, Z. Gao, W. Cai, International Journal of Modern Physics B, 23 (2009) 1803-1808.

[31] Y. Aydogdu, A.S. Turabi, M. Kok, A. Aydogdu, H. Tobe, H.E. Karaca, Applied Physics A, 117 (2014) 2073-2078.

[32] F. Chen, H. Wang, Y. Zheng, W. Cai, L. Zhao, Journal of materials science, 40 (2005) 219-221. 
[33] K. Ito, W. Ito, R. Umetsu, I. Karaman, K. Ishida, R. Kainuma, Scripta Materialia, 63 (2010) 1236-1239. [34] A.S. Turabi, H.E. Karaca, H. Tobe, B. Basaran, Y. Aydogdu, Y.I. Chumlyakov, Scripta Materialia, 111 (2016) 110-113.

[35] J. Liu, C. Jiang, H. Xu, Science China Technological Sciences, 55 (2012) 1319-1326. 